\title{
Erratum to: The impact of glutamine supplementation on the symptoms of ataxia-telangiectasia: a preclinical assessment
}

\author{
Jianmin Chen ${ }^{1 *}$, Yanping Chen ${ }^{1}$, Graham Vail ${ }^{1}$, Heiman Chow ${ }^{2,4}$, Yang Zhang ${ }^{2}$, Lauren Louie ${ }^{1}$, Jiali Li ${ }^{1,3}$, \\ Ronald P. Hart ${ }^{1}$, Mark R. Plummer ${ }^{1}$ and Karl Herrup ${ }^{1,2}$
}

\section{Erratum}

The original article [1] mistakenly omitted mention of a grant support source in the Funding sub-section, and would like to acknowledge that the work was also supported by National Key Basic Research Program of China (2013CB530900).

The original article [1] also mistakenly omits an affiliation for the co-author, Heiman Chow. The correct complete affiliation information for Heiman Chow can thus be viewed below, and in the author details for this erratum:

${ }^{2}$ Division of Life Science, The Hong Kong University of Science and Technology, Clear Water Bay, Kowloon, Hong Kong.

${ }^{4}$ Institute for Advanced Study, The Hong Kong University of Science and Technology, Clear Water Bay, Kowloon, Hong Kong.

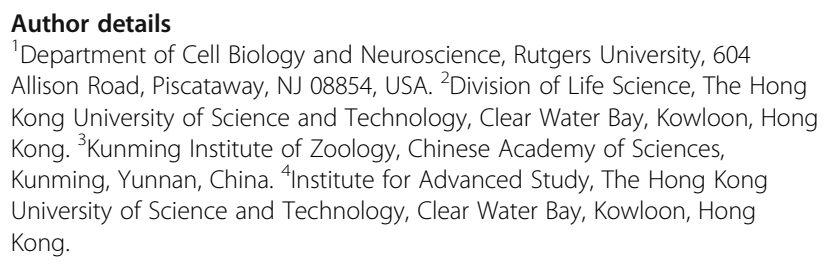

Received: 23 August 2016 Accepted: 4 January 2017

Published online: 12 January 2017

\section{References}

1. Chen J, et al. The impact of glutamine supplementation on the symptoms of ataxia-telangiectasia: a preclinical assessment. Mol Neurodegener. 2016; 11:60. doi:10.1186/s13024-016-0127-y.

\footnotetext{
* Correspondence: chen@biology.rutgers.edu

${ }^{1}$ Department of Cell Biology and Neuroscience, Rutgers University, 604

Allison Road, Piscataway, NJ 08854, USA
}

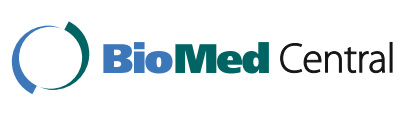

(c) The Author(s). 2017 Open Access This article is distributed under the terms of the Creative Commons Attribution 4.0 International License (http://creativecommons.org/licenses/by/4.0/), which permits unrestricted use, distribution, and reproduction in any medium, provided you give appropriate credit to the original author(s) and the source, provide a link to the Creative Commons license, and indicate if changes were made. The Creative Commons Public Domain Dedication waiver (http://creativecommons.org/publicdomain/zero/1.0/) applies to the data made available in this article, unless otherwise stated. 